\title{
Manufacturing Induced Hydrogen Embrittlement of 52100 Bearing Steel Outer Ring
}

\author{
P. Roffey
}

Submitted: 12 November 2014/Published online: 4 December 2014 (c) ASM International 2014

\begin{abstract}
An axle roller bearing failed due to full width axial cracking of the outer ring, an uncommon occurrence in roller bearings. Typically, this mechanism of failure is more consistent with inner rings that have been installed with excessive hoop stress from an incorrect interference fit on a rotating shaft. Fractography of the axial fracture revealed a shallow intergranular crack initiating from the surface of an external corner. The remainder of fracture propagation was high-cycle fatigue. Detailed metallographic analysis revealed hydrogen embrittlement on all four corners of the ring. Final machining processes, such as grinding and polishing performed on the side faces, raceway and outer surface had removed the embrittled material in these areas. This indicated the embrittlement process was not service related, but rather a result of the manufacturing heat treatment, most likely performed following the first rough cut of the ring prior to finishing.
\end{abstract}

Keywords Roller bearing - Hydrogen embrittlement . Intergranular fracture $\cdot$ Fatigue $\cdot$ Heat treatment

\section{Introduction}

The most common material used to manufacture ball and roller bearing rings is alloy steel AISI 52100, a 1.0\% carbon steel with a chromium content of $1.3-1.6 \%$ [1]. AISI 52100 is easily forged, heat treated and machined, with through hardening producing the fracture toughness

\section{P. Roffey $(\varangle)$}

Forensic Engineering \& Materials, ESR Technology,

Whittle House, 410 The Quadrant, Birchwood Park,

Warrington, Cheshire WA3 6FW, UK

e-mail: paul.roffey@esrtechnology.com required to avoid, or more specifically reduce, surface and sub-surface cracking from rolling contact fatigue (RCF).

Despite attempts to increase fracture toughness properties, RCF remains a common failure mechanism in bearings and the resistance to RCF can be summarised by the $\mathrm{L}_{10}$ fatigue life; an engineering statistical approach that estimates $90 \%$ of a particular bearing type will avoid fatigue damage in specific operating conditions, Fig. 1 [2].

Although RCF is a common bearing failure mechanism, it is not the only mechanism observed in bearings, with others including wear and abrasion, contamination-related failures (etching, corrosion or fretting corrosion), inadequate lubrication-related failures (peening, overheating, smearing) and false brinelling, true brinelling or electrical damage.

All of the mechanisms above are identified by characteristic features such as pitting, spalling or blueing on the raceways and rollers. The current study however describes an investigation of an axle roller bearing which failed due to a full width axial crack of the outer ring initiating from the outer surface and not the raceway, an uncommon failure mode in roller bearings.

\section{Results}

Macroscopic Examination

The failed roller bearing had been used on a tractor wheel axle. Each of the components, the outer ring, inner ring, cage and rolling elements, was examined in detail using stereomicroscopy. Although all of the components showed some form of damage, the most distinctive feature was the full width axial crack observed on the outer ring, Fig. 2. The crack was oriented perpendicular to the raceway and 


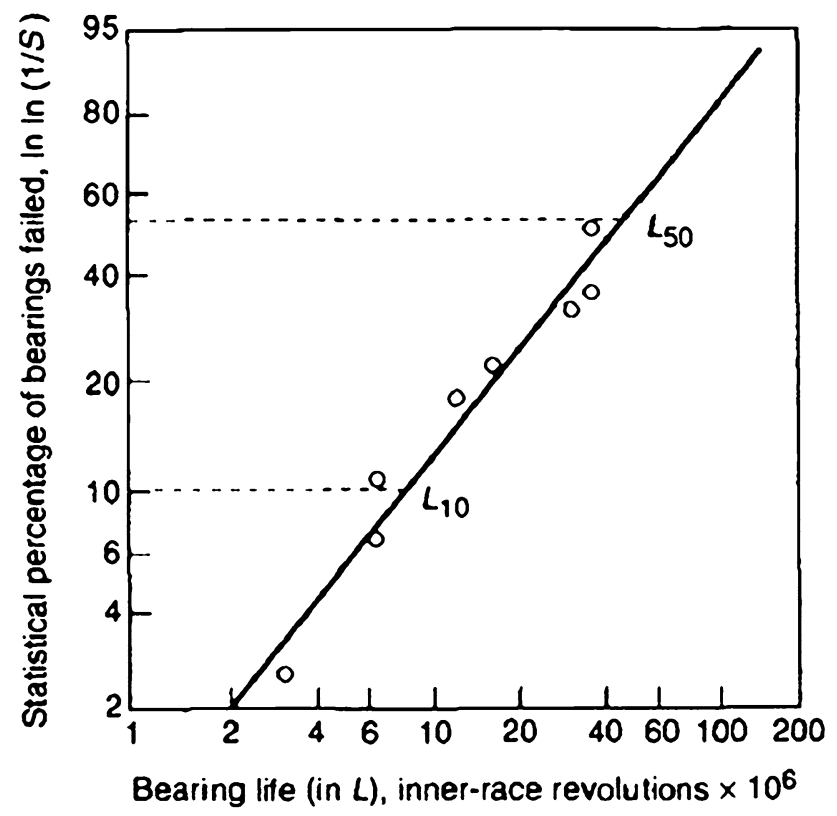

Fig. 1 Weibull plot showing the fatigue life calculations taken from Boness et al. [2]

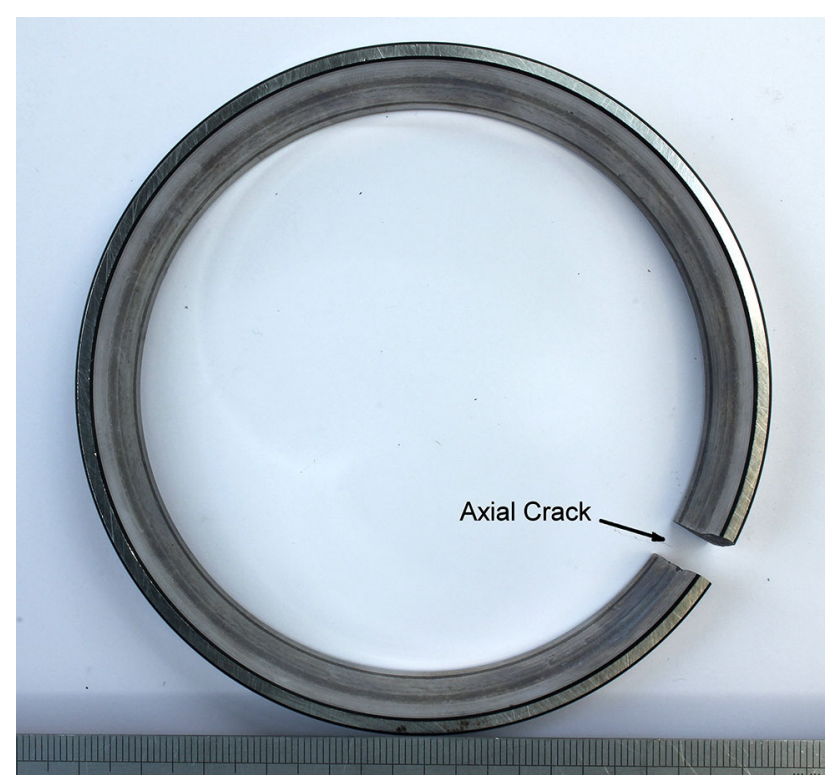

Fig. 2 Overview of cracked outer ring

showed clear evidence of origination from the machined corner near to the outer surface at the thicker diameter, Fig. 3.

Fracture direction could be identified due to propagation marks from the origin towards raceway surface. The surface possessed no coarse, jagged final overload region with only high-cycle fatigue observed across the whole section. The fracture surface had suffered limited post fracture

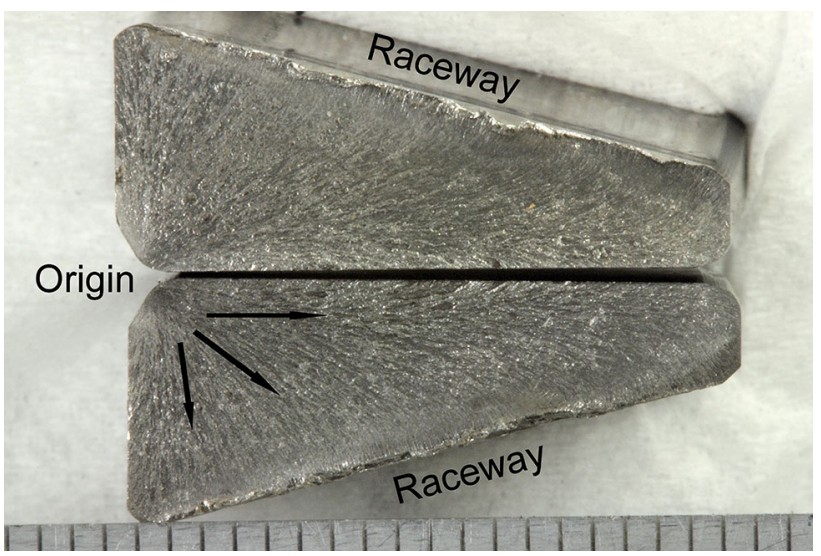

Fig. 3 Overview of fracture surface on outer ring following sectioning

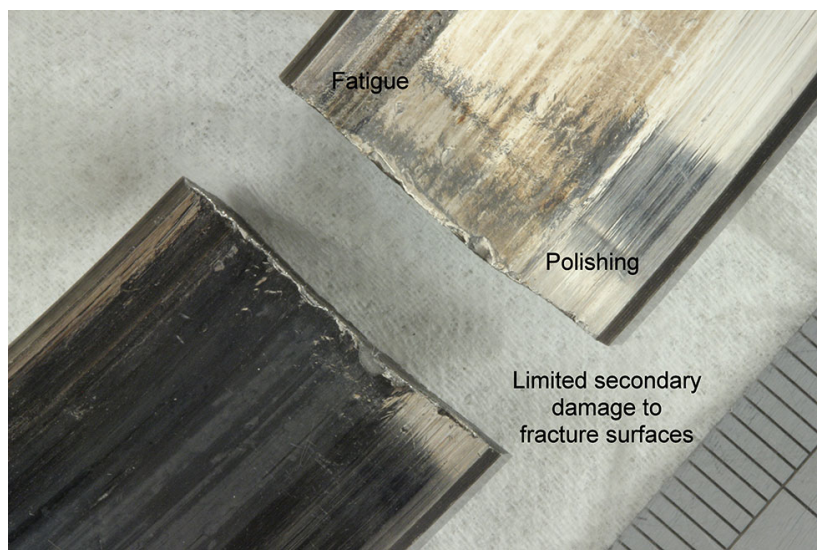

Fig. 4 Crack edges on running track indicating recent failure

damage which often impedes fractographic analysis. Light polishing and a narrow band of fatigue damage were identified on the outer ring raceway although no material loss had occurred, Fig. 4. The outer surface of the ring, which mated with the housing, had small patches of light fretting but no corrosion or mechanical damage near to the fracture origin, Fig. 5.

Two fatigue spalls were present on the raceway of the inner ring, along with polishing and secondary mechanical damage on the guide flange, Fig. 6 . The cage was intact but had undergone some plastic deformation, Fig. 7. Several of the rollers had catastrophically failed, although the majority remained in relatively good condition with slight indentation damage from entrained debris, Fig. 8.

Detailed examination of all the components, including subsequent metallography and electron microscopy, confirmed all of the features observed on the cage, rollers and inner ring were secondary failure related with the axial crack in the outer ring being the primary root cause of failure. Thus, the remainder of this study focuses only on the detailed examination of the outer ring. 


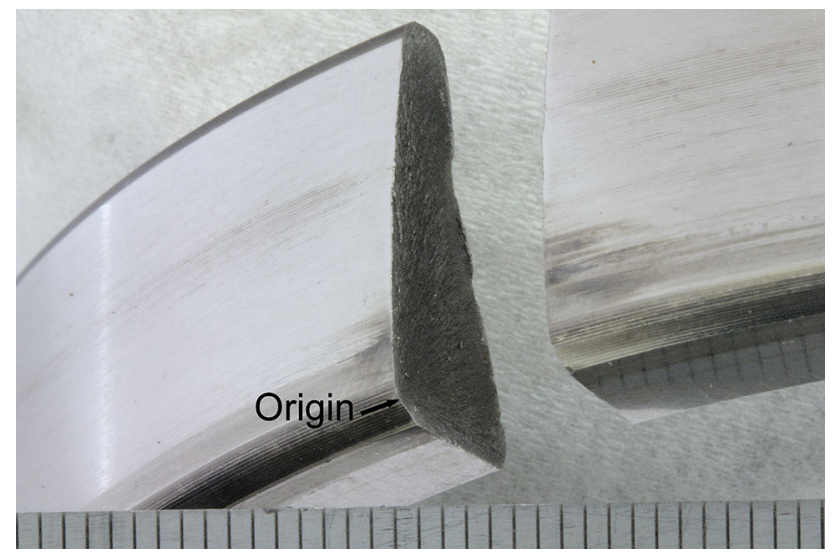

Fig. 5 Fracture surface of crack showing origin from abutment face on outer surface

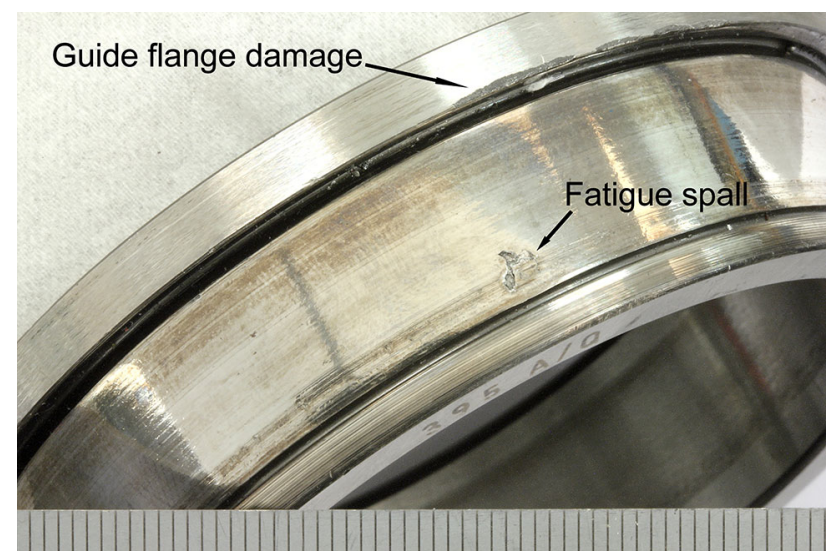

Fig. 6 Fatigue spall on inner raceway close to guide flange

\section{Scanning Electron Microscopy}

High-magnification imaging was performed on the outer ring using scanning electron microscopy (SEM). The fracture origin at machined radius possessed a $300 \mu \mathrm{m}$ intergranular (IG) crack, Figs. 9 and 10. IG cracking in bearing rings is typically associated with environmentally assisted cracking (EAC), i.e. corrosion related. Examination of the external surface close to the origin however showed no indication of corrosive attack, either general corrosion or pitting corrosion, Fig. 11. A small impact mark was identified adjacent to the origin; this however was not directly at the point of fracture and was more likely a result of the bearing removal process following failure. The remainder of the fracture surface showed a high-cyclic fatigue propagating towards the raceway with no final overload region present, Fig. 12.

\section{Optical Microscopy}

Microsections were prepared through the fracture surface to observe the crack origin, with transverse sections taken

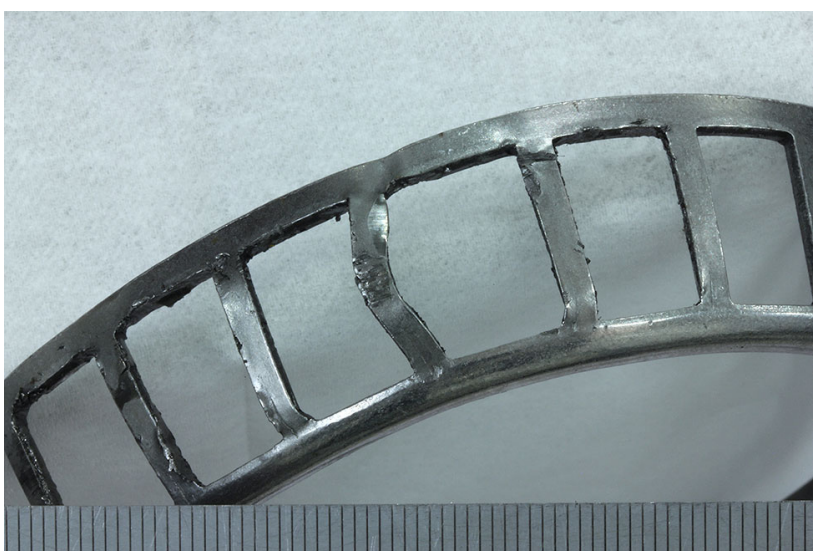

Fig. 7 Fractured cage arm, possibly due to roller seizure
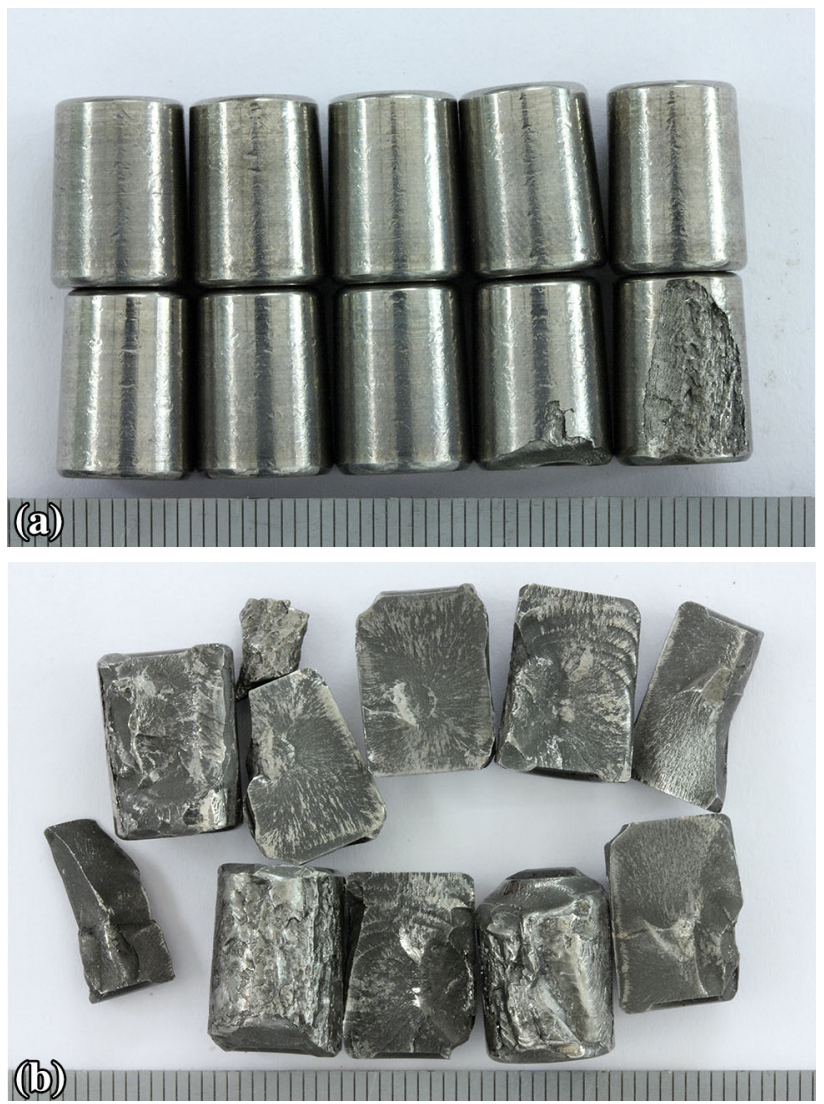

Fig. 8 Overview of rolling elements either intact or catastrophically failed

close to the fracture point to examine remote areas. The metallurgically prepared sections were etched using Picral solution to reveal the microstructure and carbide distribution.

The IG propagation when viewed in cross-section revealed a coarse morphology with no branching; this was followed by the relatively smooth fatigue propagation, Fig. 13(a). The microstructure was mottled bainitic with 

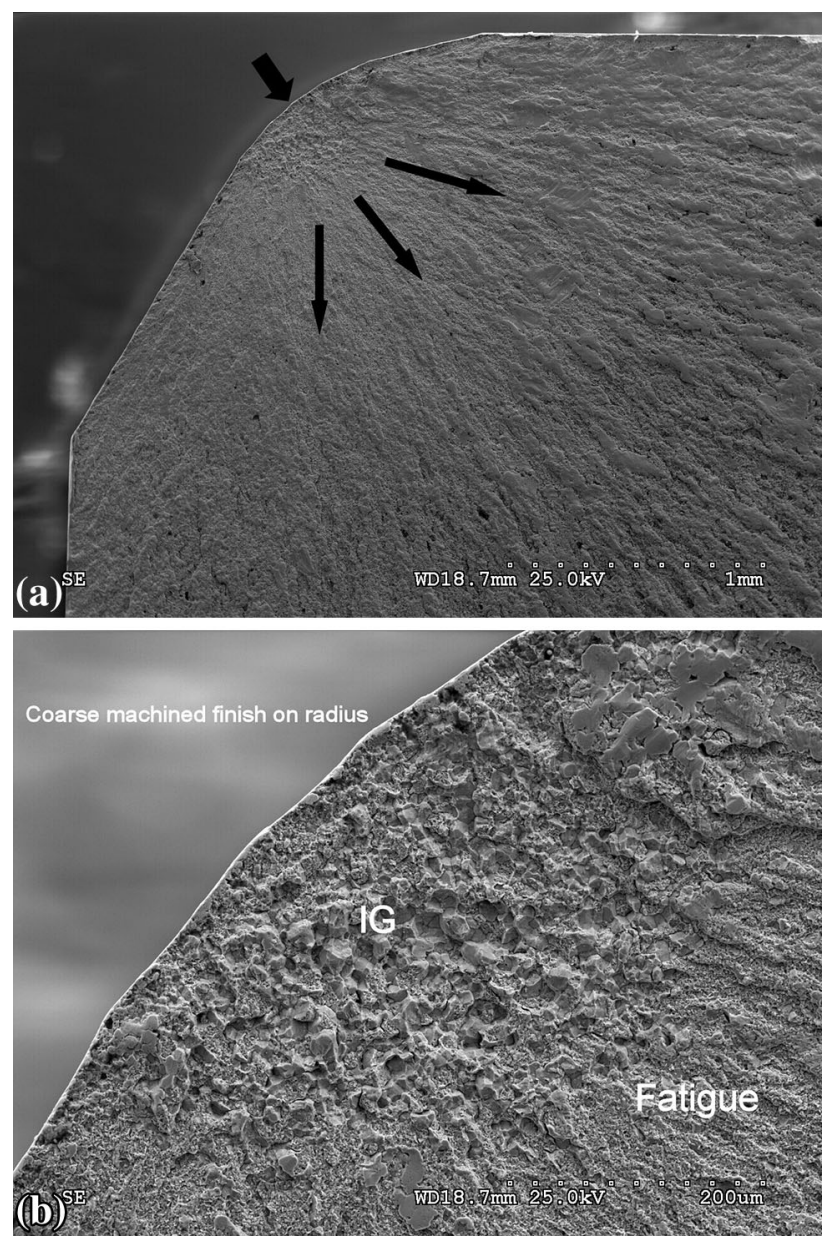

Fig. 9 (a) Overview of fracture surface-crack origin at radius on outer surface of ring and (b) fracture origin-intergranular (IG) fracture region at surface-depth $\sim 300 \mu \mathrm{m}$

prior austenite boundaries visible; the mottling is the result of localised variations in composition. High-magnification examination of the machined radius surface revealed evidence of IG embrittlement along the entire length with a high distribution of grain boundary carbides, Fig. 13(b).

White non-etching material was also present along the radii surfaces, a result of material smearing from the coarse machining process. Ideally, non-etching material should be completely removed during the final grinding and polishing operation. Further examination of all the microsections showed similar features on all four corners of the ring.

\section{Material Properties}

Compositional checks were carried out using spark optical emission spectroscopy (OES), Table 1. Alloy 52100 typically possesses a carbon content of $1 \%$ with a chromium level of $1.3-1.6 \%$; the inner ring was shown to be within specification. The phosphorous content was also below the allowable maximum level.

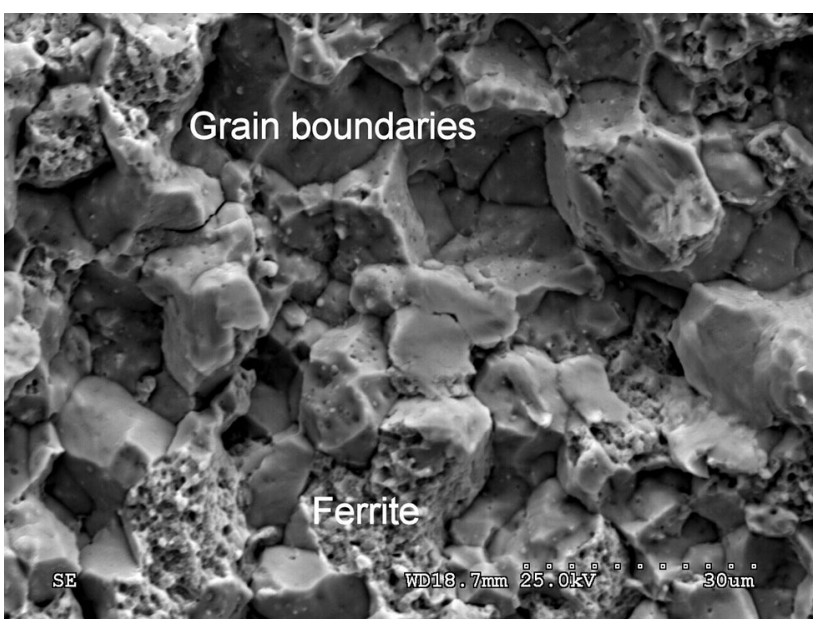

Fig. 10 Detail of IG cracking mechanism with grain boundary separation and propagation through the ferrite phase

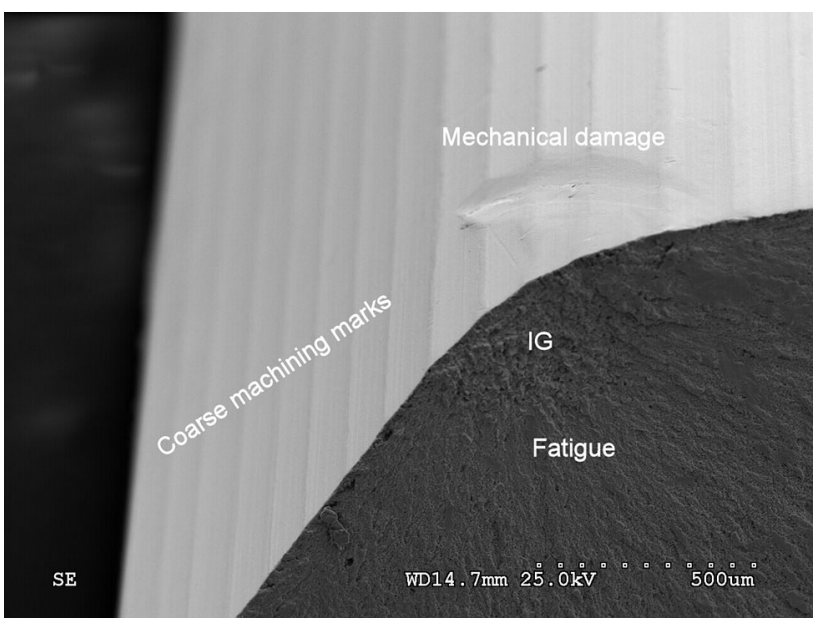

Fig. 11 Coarse machined radius close to fracture origin-note mechanical damage close to fracture but no corrosive attack

Hardness testing was performed on polished microsections using a Vickers indenter (HV) and a load of $100 \mathrm{~g}$ $\left(\mathrm{HV}_{0.1}\right)$. A profile obtained from the origin to a depth of $2 \mathrm{~mm}$ is plotted in Fig. 14. The average hardness was measured at $736 \mathrm{HV}$ with no larges increases or decreases within the embrittled region.

Generally, steels with a hardness value above $320 \mathrm{HV}$ are more susceptible to hydrogen diffusion and embrittlement; bearing steels are well above this HE threshold.

\section{Discussion}

Axial cracking is failure mode often associated with bearing inner rings having been mounted on to a shaft through an interference fit. The rings are heated to provide 


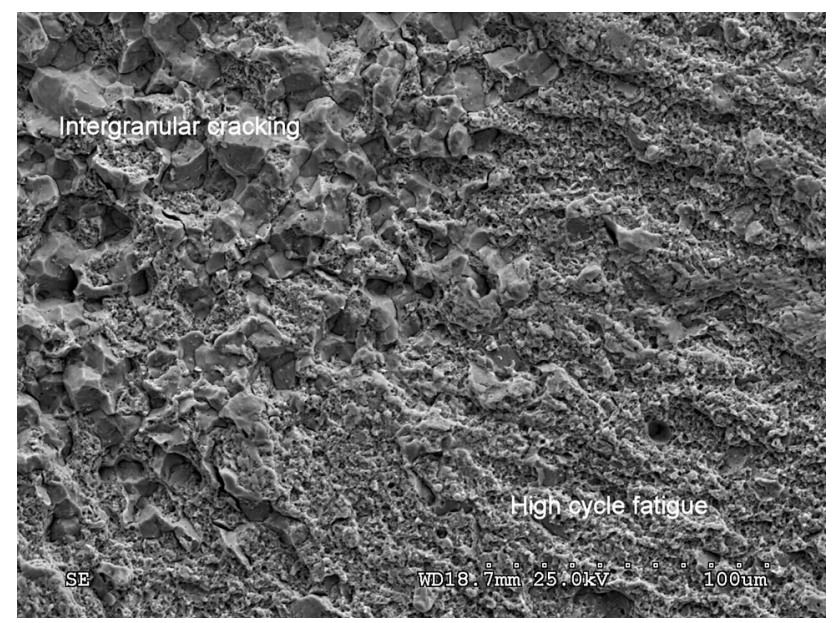

Fig. 12 Boundary between IG crack and fatigue propagation
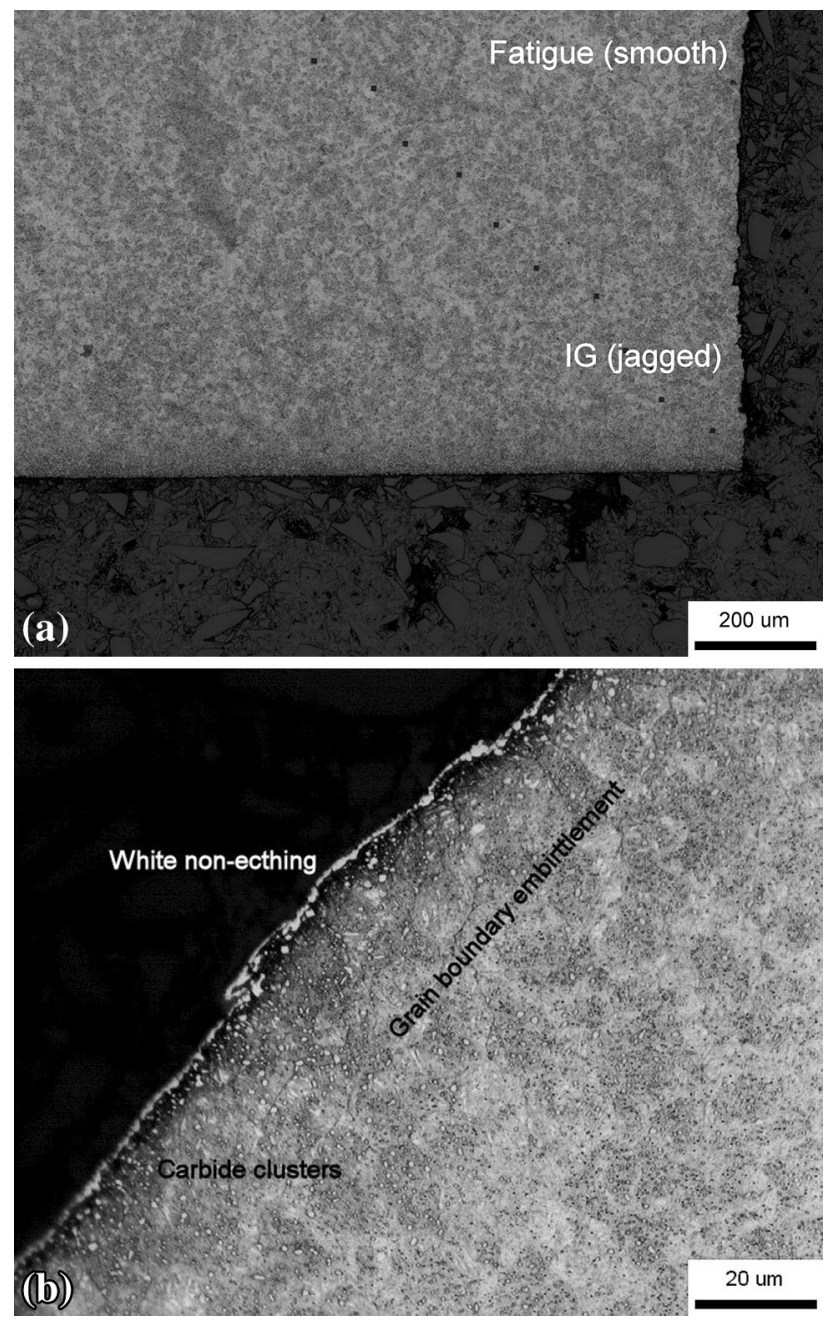

Fig. 13 (a) Cross-section through fracture surface with coarse IG crack followed by 'smooth' fatigue propagation (b) detail of embrittled surface with high carbide distribution at grain boundaries
Table 1 Spark OES chemical analysis results

\begin{tabular}{lc}
\hline Element & Mass\% \\
\hline $\mathrm{C}$ & 0.90 \\
$\mathrm{Si}$ & 0.24 \\
$\mathrm{Mn}$ & 0.37 \\
$\mathrm{P}$ & 0.006 \\
$\mathrm{~S}$ & 0.003 \\
$\mathrm{Cr}$ & 1.34 \\
$\mathrm{Mo}$ & 0.02 \\
$\mathrm{Ni}$ & 0.06 \\
$\mathrm{Al}$ & 0.016 \\
$\mathrm{~B}$ & $<0.005$ \\
$\mathrm{Cu}$ & 0.16 \\
$\mathrm{Nb}$ & $<0.01$ \\
$\mathrm{Ti}$ & $<0.01$ \\
$\mathrm{~V}$ & $<0.01$ \\
\hline
\end{tabular}

a small amount of expansion allowing the ring to slide over the shaft. Cooling then shrinks the ring on to the shaft surface, resulting in the interference fit. This process inherently generates a tensile stress in the ring. Excessive hoop stress may then result in the perpendicular axial cracking. This mode of cracking through an outer ring, however, which typically sits in a housing with a small amount of clearance, is rarely observed. The clearances between the ring and housing are associated with strict tolerances, typically $150 \mu \mathrm{m}$. If this is exceeded, failure tends to occur due to RCF, resulting in a large amount secondary damage as the rolling elements and ring have the freedom to move and contact each other.

The examination of the outer ring showed little evidence of secondary damage with limited rubbing damage, indicating that the clearance was likely to have been correct, not allowing the two fractures to contact each other following failure. This was further supported due to uninterrupted high-cycle fatigue propagation through the full cross-section with no final overload region.

The lack of substantial raceway damage eliminated the possibility of lubrication issues or RCF as contributions to failure. Furthermore, no evidence of corrosion was seen within the contact zone or on the external surfaces which eliminated the ingress of water during service.

Intergranular cracking of bearing rings is a failure mode often associated with EAC mechanisms such as stress corrosion cracking (SCC) from corrosive electrolytes such as moisture, water or lubricants. SCC is an IG mechanism but typically initiates from a corrosion pit and propagates through branched IG cracks; no branching or corrosion was observed. Other forms of hydrogen-induced cracking include cracking due to the presence of volatile substances 


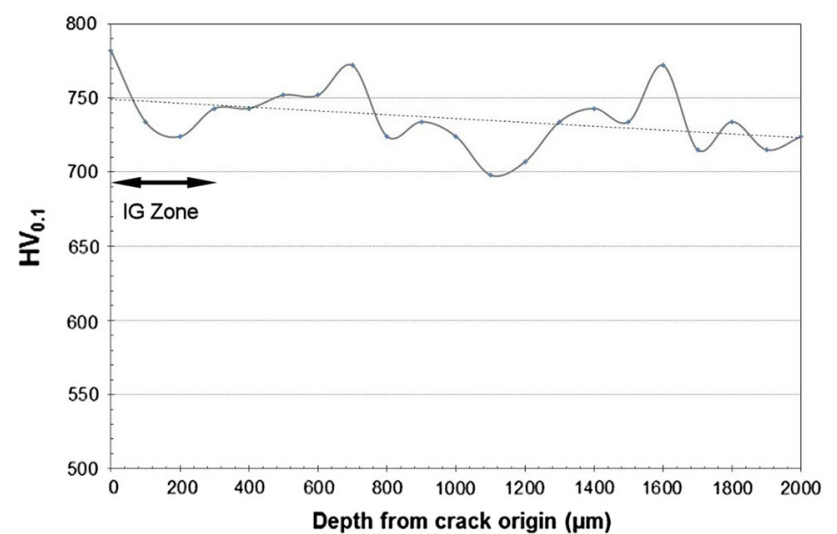

Fig. 14 Hardness profile from outer surface near fracture origin on outer ring to a depth of $2 \mathrm{~mm}$

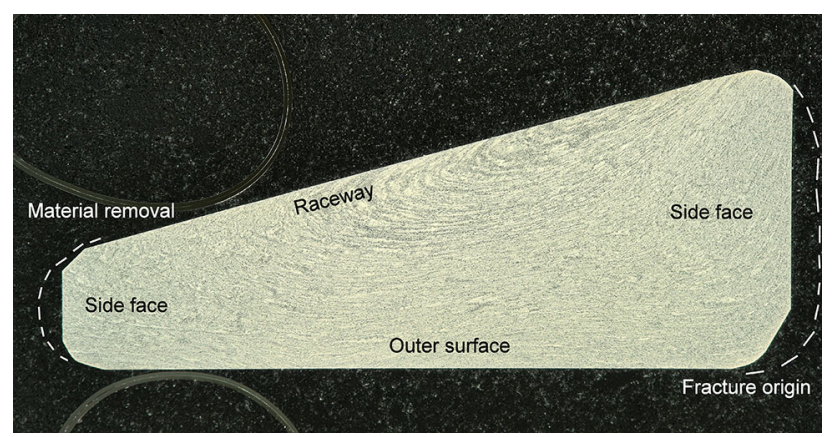

Fig. 15 Overview of etched transverse microsection through outer ring showing forged structure. Dashed lines indicate most likely forging shape prior to machining

such as hydrogen sulphide in sour gas; this particular bearing however would not have been exposed to such environments. The absence of corrosion however eliminated in-service embrittlement with the likely source being during manufacture.

Optical microscopy of microsections showed embrittled material present on all four corners of the ring along with a high distribution of grain boundary carbides. The surface of the corners also possessed white non-etching material, remnants of the coarse machining process. The side face, raceway and outer surface however showed none of these features.

The initial shape of a forged bearing ring means that the rounded edges on the side faces require a greater amount of material removal from these locations to achieve tolerance and surface finish. Likewise, the outer surface and raceway will undergo substantial material removal, with the raceway being finished to a polished surface. The corners of the ring, or radii, however require less strict tolerance and can be left with a relatively coarse machined finish, Fig. 15.

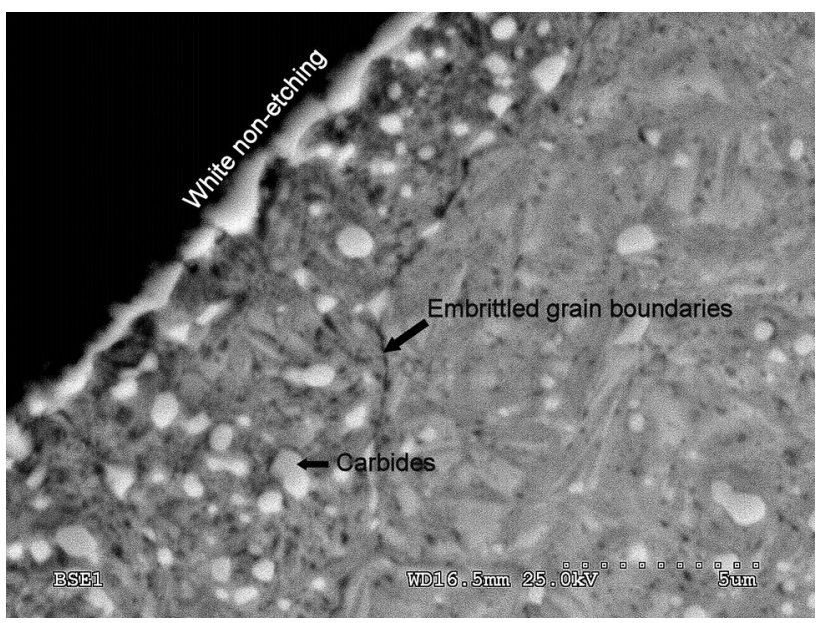

Fig. 16 SEM micrograph showing IG embrittlement, carbide clustering and white non-etching material on the machined surface

Following this first rough cut a heat treatment is then performed, before final grinding and polishing processes. The presence of the defective material on the corners would indicate the embrittlement occurred during the first heat treatment process, an excluded possibilities of embrittlement during the final stages of finishing.

The presence of embrittled material will increase the risk of crack initiation under shock loading conditions, and the service duty of a tractor axle will undoubtedly lead to shock loading. Grain boundary embrittlement will result in IG cracking through the embrittled zone, this will then act as a stress concentration or notch for fatigue propagation through the remainder of the section under high-cycle/lowload cyclic conditions.

A common form of material embrittlement during the manufacturing stage is hydrogen diffusion into the structure, i.e. hydrogen embrittlement (HE), particularly for materials above the $320 \mathrm{HV}$ threshold. Thus, heat treatments should be performed correctly to avoid hydrogen diffusion. The diffusion of the hydrogen follows the path of least resistance along ferrite grain boundaries, through the ferrite phases and along the interface between the ferrite and pearlite phases resulting in the loss of ductility and tensile strength. Grain boundary separation and separation through the ferrite phase were observed on the fracture surface, Fig. 16.

Bearing steels possess a network of dispersed carbides though the structure, or more precisely along the grain boundaries. It is the presence of carbides and unwanted defects such as non-metallic inclusions (both sub-surface and surface breaking) that often result in RCF. Furthermore, the carbides may also act as traps under hydrogen diffusion conditions, further increasing susceptibility where carbide distribution is high [3].

Heat treatments aim to refine the microstructure by increasing homogeneity. This is achieved by dissolving the 
carbides (or reducing the size) and transforming the austenite phase to bainite. A post-heat treatment tempering is then performed to achieve desired toughness $[4,5]$. The heat treatments are performed incorrectly, i.e. incorrect temperature or insufficient time, where the carbide network will remain unrefined or become clustered as observed in this study. This increases the risk and likelihood for RCF and grain boundary embrittlement.

High levels of phosphorous have also been shown to increase the propensity of hydrogen diffusion, particularly at crack tips, which drives cracking forward, although the levels in the outer ring measured by Spark OES were acceptable [6].

It should be noted that localised carbide formation may also occur during machining processes; however, the temperature required to form the carbides would result in clear temperature damage, and the bearing would have been rejected at the quality control stage, or would have been clearly visible at installation/failure investigation.

To allow the steel to effuse the hydrogen and avoid embrittlement, baking processes can be carried out to components. This process however may be only applicable to certain material and may affect the materials properties, thus it should be performed to the correct parameters.

\section{Conclusions}

The primary root cause of failure of the outer ring was due to intergranular embrittlement, or $\mathrm{HE}$, from incorrect heat treatment performed prior to machining.
Material removal from the side faces, outer surface and the running track removed the embrittled layer although only coarse machining of the corners left the embrittled material in place.

A relatively shallow IG crack on the radii of the outer surface of the outer ring, most likely the result of a shock load, created a notch for fatigue initiation.

High-cycle/low-load operation of the bearing propagated a fatigue crack through the bearing ring. Fracture of the outer ring increased the clearance, which lead to the secondary damage to the rollers, cage inner and outer ring sunning surfaces.

\section{References}

1. ASTM International, Failures of Rolling-Element Bearings. Volume 11 Failure Analysis and Prevention. Metals Handbook, 9th edn. (ASTM International, West Conshohocken, 1990), p. 508

2. R.J. Boness, W.R. Crecelius, W.A. Ironside, C.A. Moyer, E.E. Pfaffenberger, J.V. Poplawski, Current practice, in Life Factors for Rolling Bearings, ed. by E.V. Zaretsky (Society of Tribologists and Lubrication Engineers, Park Ridge, 1992), pp. 5-7

3. D. Ray, L. Vincent, B. Coquillet, P. Guirandenq, Hydrogen embrittlement of a stainless ball bearing steel. Wear 65, 103-111 (1980)

4. D.W. Hetzner, Continued developments in easily carburizable high speed steel alloys, in Bearing Steel Technology-Advances and State of the Art in Bearing Steel Quality Assurance, ed. by M. Beswick (West Conshohocken, ASTM International, 2007), pp. 198-206

5. C.A. Stickels, Carbide refining heat treatments for 52100 bearing steel. Metall. Trans. 5(4), 865-874 (1974)

6. J.H. Westbrook, NACE-5, in SCC and Hydrogen Embrittlement of Iron Base Alloys, ed. by I. Hochman, R.W. Staehle (NACE, Houston, 1977), pp. 30-36 